\begin{tabular}{|c|c|}
\hline Title & $\begin{array}{l}\text { Development of rear-impeller axial flow blood pump for realization of axial flow blood pump installed at aortic valve } \\
\text { position }\end{array}$ \\
\hline Author(s) & Okamoto, Eiji; Y ano, Tetsuya; Inoue, Y usuke; Shiraishi, Y asuyuki; Y ambe, Tomoyuki; Mitamura, Y oshinori \\
\hline Citation & $\begin{array}{l}\text { A rtificial organs, 43(9), 828-833 } \\
\text { https://doi.org/10.1111/aor.13476 }\end{array}$ \\
\hline Issue Date & $2019-09$ \\
\hline Doc URL & http:/hdl.handle.net/2115/79206 \\
\hline Rights & $\begin{array}{l}\text { This is the peer reviewed version of the following article: Development of rear-impeller axial flow blood pump for } \\
\text { realization of axial flow blood pump installed at aortic valve position, which has been published in final form at } \\
\text { http://doi.org/10.1111/aor.13476. This article may be used for non-commercial purposes in accordance with Wiley } \\
\text { Terms and Conditions for U se of Self-A rchived V ersions. }\end{array}$ \\
\hline Type & article (author version) \\
\hline File Information & Development of the rear impeller pump_hokudai.pdf \\
\hline
\end{tabular}

Instructions for use 
Development of rear-impeller axial-flow blood pump for realization of axial flow blood pump installed at aortic valve position

Eiji Okamoto, Tetsuya Yano ${ }^{2}$, Yusuke Inoue ${ }^{3}$, Yasuyuki Shiraishi ${ }^{3}$, Tomoyuki Yambe ${ }^{3}$, Yoshinori Mitamura $^{4}$

1)Sapporo liberal arts center, Tokai University

2)Graduate school of Science and Engineering, Hirosaki University

3) Institute of Development Aging and Cancer, Tohoku University

4)Hokkaido University

\section{Eiji Okamoto}

Graduate School of Science and Engineering, Tokai University

Minami-sawa 5-1-1-1,Minami-ku, Sapporo, Japan,005-8601

Email:okamoto29@tsc.u-tokai.ac.jp

$+81-11-571-5111$ ext.2512 
Abstract

In this study, rear-impeller axial-flow blood pumps (RIAFBP) were developed to realize a transvalve axial ventricular assist device (VAD) which consists of the latter blood pump and a polymer monomembrane aortic valve, such as the jelly-fish valve. The motor of the RIAFBP is installed in the left ventricle, and its impeller is placed at the aortic valve position.

In the prototype RIAFBP, the rotation of the motor is sustained by polyethylene bushes. The RIAFBP has a length of $50 \mathrm{~mm}$ and diameter of $19.6 \mathrm{~mm}$.

The miniature RIAFBP has the same construction as that of the prototype; however, it employs a ceramic bearing and fin bearing to improve endurance and to reduce blood stagnation. The miniature RIAFBP has a length of $63 \mathrm{~mm}$ and diameter of $12 \mathrm{~mm}$.

Both RIAFBPs were examined by an in vitro experiment using a $33 \%$ glycerin solution. The prototype RIAFBP achieved a maximum pump outflow of $8.5 \mathrm{~L} / \mathrm{min}$ against a pump head of 100 $\mathrm{mmHg}$ at a rotational speed of $12000 \mathrm{rpm}$. The miniature RIAFBP achieved $7 \mathrm{~L} / \mathrm{min}$ against a pump head of $70 \mathrm{mmHg}$ at a rotational speed of $21600 \mathrm{rpm}$.

In conclusion, the miniature RIAFBP has enough pump performance to realize the trans-valve axial VAD.

Keywords: Artificial heart, Left ventricular assist device, Axial flow blood pump, Jellyfish valve 
Introduction

Various rotary blood pumps have been clinically used as bridges to heart transplantation, and recovery and for destination therapy (1). These devices are implanted parallel to the natural heart between the left ventricle and ascending aorta using conduits consisting of foreign materials.

Here, a new axial-flow blood pump, a "valvo pump", which is implanted at the aortic valve position, was evaluated $(2,3)$. It showed sufficient hydrodynamic performance to support cardiac function and it had acceptable hemolysis characteristics, but the size of the valvo pump was too large to implant into aortic valve position(4). Miniaturization of the valvo pump is difficult owing to is mechanical structure, and the expected lifetime of the ferromagnetic fluid seal is approximately two years(5). Then, we developed a new axial flow blood pump (2nd valvo pump) using our original blushless motor and a passive magnetic bearing (6). In addition, the hemodynamic change under ventricular assist device(VAD) using the 2nd valvo pump connected in series with the natural heart was investigated using in vivo studies $(7,8)$. The experimental results showed that the 2 nd valvo pump enabled pulsatile blood perfusion to the end- organs downstream from the pump without rotational speed modulation; however, the potential risk of decreased blood flow caused by a pressure drop upstream of the pump was measured. Thus, such as the concept of the valvo pump, upstream of the coronary sinus is a suitable position for implantation of an axial VAD to avoid disturbance of coronary and cerebral circulation (8). However, miniaturization of the 2 nd valvo pump is difficult because we were not able to generate enough magnetic repulsion force in a miniature passive magnetic bearing.

Wang et al. developed a reversible axial VAD implanted at the ascending aorta, and the blood perfusion disturbance on the coronary flow was avoided by the synchronized forward/reverse rotation of the impeller with the cardiac cycle as an intra-aortic balloon pump(IABP) counter pulsates with the left ventricle to increase coronary perfusion (9). However, it is difficult to design an upstream and downstream diffuser to maintain pump performance during reversible operation (10). 
Letzen et al. developed the intra-aortic axial VAD in which the impeller is placed at a rear position of the motor, and is coupled with the encapsulated motor by magnetic coupling force. However, friction in magnetic coupling causes energy loss and could cause hemolysis and thrombus formation (11).

Smith et al. developed an intra-atrial blood pump using a cylinder bearing, and they evaluated its performance by an in vivo experiment (12). However, the endurance and hemocompatibility of the cylinder bearing is unknown.

In this study, a new axial VAD was developed with an impeller placed at the rear of the motor as a torpedo (13). The motor region of the axial VAD is placed in the left ventricle, and the axial VAD is passed through the aortic valve. The impeller is placed at the aortic valve position, and it perfuses the blood from the left ventricle to the ascending aorta just behind the aortic valve leaflets (Figure 1). This configuration supports systemic, cerebral, and coronary circulation using the pulsatile flow generated by the natural heart.

The purpose of this study is to develop this new cardiac support device, a trans-valve axial VAD. In this study, a prototype rear-impeller axial-flow blood pump(RIAFBP) was developed for application in a trans-valve axial VAD, and its pump performance was evaluated by an in vitro experiment. The prototype RIAFBP was minimized to realize the trans-valve axial VAD.

\section{Material and Method}

Prototype rear-impeller axial-flow blood pump

Figure 2(a) shows the construction of a prototype RIAFBP. The RIAFBP has two parts: a motor and an impeller. A feature of the valvo pump is that the impeller is separated from the motor $(2,3)$. In contrast to the clinically used axial VADs whose impeller is integrated with the rotor, the separation between the rotor and impeller allows a flexible impeller design, and the well-established classical impeller design theories (14) can be applied to design the impeller $(2,3)$. 
The motor consists of a stator and neodymium magnets rotor, and the stator and rotor were designed using motor design software (JMAG-express, JSOL Co., Tokyo, Japan) to achieve a motor torque of $0.01 \mathrm{~N}-\mathrm{m}$ and an output power of $10 \mathrm{~W}$ at a rotational speed of $10000 \mathrm{rpm}$.

The rotational motion of the rotor is sustained by polyethylene bushes without a mechanical seal. The RIAFBP has two flow paths: the space between the rotor and stator and outside of the stator. The rotor has a single vine sub-impeller to eliminate the stagnation of blood flow between the rotor and stator. A main impeller has four vanes, and it draws the blood through four intakes at the back of the motor, and hydrodynamic energy is added to the straightened blood flow.

Figure 2(b) shows the experimental model of the RIAFBP used to examine the pump performance in an in vitro experiment. The prototype RIAFBP has a length of $50 \mathrm{~mm}$ and diameter of $19.6 \mathrm{~mm}$, and the length of the pump placed in the left ventricle is $35 \mathrm{~mm}$. In the theoretical design of main impellers, the impeller diameter was set to $17.3 \mathrm{~mm}$. The vane number, vane inlet and outlet angle, and hub ratio and hub length were determined by the angular momentum theory (14) under changing operational point and estimated coefficient. Consequently, we designed over 20 kinds of the main impeller and the optimum one was selected from the result of the in vitro experiment. The pump housing and impellers were made from polyurethane using a CAD/CAM system (MDX-40, Roland DG, Hamamatsu, Japan).

Miniature rear-impeller axial-flow blood pump

Figure 3(a) shows the construction of the miniature RIAFBP. The concept of the downsizing is to reduce the diameter of a motor while maintaining the motor output. The construction of the miniature RIAFBP is the same as that of the prototype pump; however, the miniature RIAFBP employs a ceramic bearing upstream of the rotor, and a fin bearing using three guide vanes are installed downstream of the rotor instead of the polyethylene bushes. The motor is redesigned to be a high- 
speed low-torque motor using motor design software. The estimated motor performance is a motor torque of $0.0038 \mathrm{Nm}$ and output $8 \mathrm{~W}$ at a rotational speed of $20000 \mathrm{rpm}$.

Figure 3(b) shows the miniature RIAFBP. The miniature RIAFBP has a length of $63 \mathrm{~mm}$ and diameter of $12 \mathrm{~mm}$. The diameter of the miniature RIAFBP is designed to be half that of the aortic valve. The main impeller has three vanes and an outer diameter of $10 \mathrm{~mm}$. As in the case of the prototype RIAFBP, the impeller diameter was set to $10 \mathrm{~mm}$, the vane number, vane inlet and outlet angle, and hub ratio and hub length were determined by the angular momentum theory (14) under changing operational point and estimated coefficient. Consequently, we designed 14 kinds of main impellers and the optimum one was selected from the result of the in vitro experiment. The miniature RIAFBP was also made from polyurethane.

\section{Results}

Prototype rear-impeller axial flow blood pump

The prototype RIAFBP was examined in an in vitro experiment using a $33 \%$ glycerin solution as the working fluid. The RIAFBP was driven by a sensor less motor driver (DECS 50/5, Maxon Japan, Tokyo, Japan). We designed over 20 kinds of impellers and selected the optimum one based on hydrodynamic efficiency by the in vitro experiments. The results showed that an impeller with four vanes, inlet and outlet angle of $15^{\circ}$ and $18^{\circ}$, and hub length and hub ratio of $3.5 \mathrm{~mm}$ and 0.58 , respectively, showed good hydrodynamic performance.

Figure 4(a) shows the pump performance of the prototype RIAFBP. The prototype RIAFBP had a pump outflow of $5 \mathrm{~L} / \mathrm{min}$ against a pump head of $100 \mathrm{mmHg}$ at a rotational speed of $9600 \mathrm{rpm}$, and the hydrodynamic efficiency was calculated as 7-8\%.

The miniature RIAFBP was also examined in an in vitro experiment using a $33 \%$ glycerin solution, and as in the case in the prototype RIAFBP, we selected the optimum impeller from the 14 kinds of 
impeller designs based on the hydrodynamic efficiency. The results show that an impeller with three vanes, inlet and outlet angle of $19^{\circ}$ and $31^{\circ}$, and hub length and hub ratio of $4 \mathrm{~mm}$ and 0.6 , respectively, showed excellent pump performance.

Figure 4(b) shows the pump performance of the miniature RIAFBP. The miniature RIAFBP had a pump output of $3 \mathrm{~L} / \mathrm{min}$ against a pump different pressure of $100 \mathrm{mmHg}$ at a rotational speed of 19200 rpm. The hydrodynamic efficiency of the impeller was 6-7\%.

\section{Discussion}

The new concept of the axial VAD in 1989 has several merits. An axial VAD serially connected with the natural heart, such as the valvo pump, can support blood circulation with pulsatile flow generated by the natural heart without pump speed modulation $(15,16)$. However, realization of the valvo pump concept has not occurred because it is difficult to develop a miniature high- power motor to meet the requirement of the valvo pump under current motor technology. Thus, a new concept of the valvo pump was proposed: The trans-valve axial VAD, in which the motor is installed in the left ventricle, and the impeller is placed at the aortic valve position. In this study, initially, the basic structure and hydrodynamic performance of a RIAFBP was confirmed by developing the prototype, and then, a miniature RIAFBP was developed for the trans-valve axial VAD. The diameter of the miniature RIAFBP was approximately half that of the aortic valve, and it had a maximum pump output of 7 $\mathrm{L} / \mathrm{min}$, which is adequate pump performance for a left ventricular assist device.

However, the shape of the H-Q curve of each pump is different, as shown in figures 4(a) and (b). In general, a typical H-Q curve of an axial-axial flow pump includes a part with a straight line and a part with a curved line (13). The prototype RIAFBP operates within the part with the straight line while the miniature RIAFBP operates within the parts with the straight line and curved line. The $\mathrm{H}^{-}$ Q curve depends on the impeller and the configuration of the inlet and outlet. Then, the H-Q curve of 
the miniature RIAFBP can be made similar to the liner characteristics.

The magnetic levitation as a non-contact bearing is one of the best options for rotational blood pumps $(17,18)$;however, it may be technically impractical to develop a magnetic levitation bearing for small axial VADs. The miniature RIAFBP employs ceramics and fin bearings belonging to a second-generation blood pump, such as the Heart mate 2 and Jarvik 2000 (18). Further improvement of the bearings is required for long-term endurance and to prevent thrombus formation. However, these bearings could sustain the rotational motion in the miniature RIAFBP.

An impeller with a superior hydrodynamic efficiency is expected to minimize hemolysis (19). In this study, the highest hydro dynamically efficient impeller was chosen to be optimum. However, impeller and guide vane improvement, including a detailed design, is required for further reduction of hemolysis and thrombus formation by hemolysis tests and a CFD analysis.

The hydrodynamic efficiency of the prototype RIAFBP was estimated to be $7-8 \%$, while that of the miniature RIAFBP was estimated as $6-7 \%$. The maximum efficiency of the miniature axial flow blood pump developed by Smith et al. is $20 \%$ (20), but this result was obtained using a bigger motor in the in vitro measurement system.

On the other hand, we measured the hydrodynamic efficiency by installing the impeller in the motor used and it was driven by the sensor less motor driver. In the sensor less motor driver, the electrical loss increased with an increase in motor load and motor speed because the switching timing of the stator excitation current was deviated in the case of a low-torque motor, such as our blushless motor.

However, in practice, it is difficult to distinguish between the hydrodynamic loss, electro-mechanical loss of the motor, and electrical loss of the driver circuit. Therefore, the hydrodynamic efficiency of the impeller could be underestimated. Further study is required to reduce the energy losses by improving the impeller, motor, and electric circuit. 
An important issue for the trans-valve axial VAD is wear on the aortic valve. The miniature RIAFBP is combined with a polymer monomembrane valve, such as the jelly fish valve (21), to realize the trans-valve axial VAD (Figure 5). The trans-valve axial VAD can be stitched to the base of the aorta, similar to artificial aortic valve replacement. The jelly-fish valve is a superior artificial heart valve, and its hemocompatibility and long-term endurance has been confirmed by chronic animal experiments. Conversely, Jarvik et-al. developed the Valve-pump, similar to the valvo pump, that combined a miniature axial VAD with a tissue valve (22). The structures of the jelly-fish valve and tissue valve are different, and the miniature axial VAD structurally fits well to the jelly-fish valve, rather than the tissue valve by replacing the central axle of the jelly-fish valve to the axial VAD. But further study is required on the effects of the interaction between the valve and pump on the pump performance in an in vitro experiment, and to investigate a proposed surgical procedure by an in vivo experiment.

Another potential issue of the trans-valve axial VAD is the wiring of the motor lead wires. We are planning to wire the motor lead wires through a tunnel inside the housing wall and through a tunnel inside the spoke of the polymer monomembrane valve to the valve ring. This wiring has the advantage of preventing direct contact between the motor wires and blood, and can reduce the risk of thrombus formation.

In further development, a miniature RIAFBP with a diameter less than $8 \mathrm{~mm}$ could be installed through catheterization, such as a transcatheter aortic valve replacement (23), with a stent.

The hydrodynamic performance of the trans-valve axial VAD should be evaluated in in vitro and in vivo experiment.

Conclusion

In this study, prototype and miniature RIAFBPs were developed to realize a trans-valve axial VAD. 
The miniature RIAFBP was combined with a polymer monomembrane aortic valve, such as the jelly fish valve, create a valvo pump.

The miniature RIAFBP has enough pump performance for a trans-valve axial VAD application; however, further studies including CFD analysis and hemolysis tests are required to reduce the risk of hemolysis and thrombus formation.

\section{Acknowledgement}

This study was supported by KAKENHI (Grant-in-Aid for Scientific Research-C (No. 16K01375)), and supported by research program of Institute of Development, Aging and Cancer, Tohoku University (No.2018_8).

\section{Reference}

1)Kirklin KJ, Pagani FD, Kormos RL, Stevenson LW, Blume ED,Myers SL, Miller MA, Baldwin JT,Young BJ,and Naftel DC. Eighth annual INTERMACS report: special focus on framing the impact of adverse events. J. Heart Lung Transplant 2017; 36:1080-1086

2) Mitamura Y, Yozu R, Tanaka T. The valvo-pump: axial nonplusatile blood pump. ASAIO Trans 1991; 37:M510-512

3) Mitamura Y, Nakamura H, Okamoto E, Yozu R, Kawada S, Kim DW : Development of the Valvo Pump: An axial flow pump implanted at the heart valve position. Artificial Organs 1999; 23:566-571 4)Mitoh A, Yano T, Sekine K, Mitamura Y, Okamoto E, Kim DW, Yozu R, Kawada S,“Computational Fluid Dynamics Analysis of an Intra-Cardiac Axial Flow Pump”, Artificial Organs27(1): 34-40, 2003 5)Mitamura Y, Kido K, Yano T, Sakota D, Yambe T, Sekine K, Okamoto E, A Hydrodynamically suspended magnetically sealed mechanically noncontact axial flow blood pump:design of a hydrodynamic bearing”,Artificial Organs 31(3):221-224,2007 
6) Okamoto E, Ishida Y, Yano T, Mitamura Y. Passive magnetic bearing in the 3rd generation miniature axial flow pump-the valvo pump 2. J.Artificial Organs 2015;18:181-184

7)Okamoto E, Yano T, Shiraishi Y, Miura H, Yambe T, Mitamura Y. Initial acute animal experiment using a new miniature axial flow pump in series with the natural heart. Artificial Organs 39(8):701704,2015

8) Okamoto E, Yano T, Miura H, Shiraishi Y, Yambe T, Mitamura Y, Measurement of hemodynamic changes with the axial flow blood pump installed in descending aorta, J.Artificial Organs 2017;20:390393

9)Wang Y, Hsu PL, Love HC, Timms DL, McMahon RA, In vitro study of an intra-aortic VAD: Effect of reverse-rotating mode on ventricular recovery. Proc. 37th annual international conference of the IEEE Engineering in Medicine and Biology 2015;:274-277

10)Wang Y, Smith PA, Timms DL, Hsu PL, McMahon A, In vitro evaluation of the dual-diffuser design for a reversible rotary intra-aortic ventricular assist device. Artificial Organs 2016;40:884-893

11)Letzen B, Park J, Tuzun Z, Bonde P, Design and development of a miniaturized percutaneously deployable wireless lift ventricular assist device: Early prototypes and feasibility testing. ASAIO J. 2018;64:147-153

12)Smith PA,Wang Y, Bieritz SA,Conger JL,Sampaio LC, Cohn WE, Frazier OH, In vivo feasibility of an intra-atrial blood pump for partial support of the left ventricle. 40th annual international conference of IEEE EMBC 2018;:4520-4528

13) Okamoto E, Yano T, Miura H, Shiraishi Y.Yambe T, Mitamura Y,Development of Axial Flow Blood Pumps That Implanted at Aortic Valve Position to Realize Concept of Valvo Pump, Abstracts of ASAIO 63th annual conference 2017;:4

14)Stepanoff A.J. Centrifugal and axial flow pumps 2nd ed. Florida: Krieger Publishing Company;1957 
15)Fukamachi K, Karimov J,Sunagawa G,Horvath D, Byram N, Kuban B, Dessoffy R, Sale S, Golding L,Moazami N, Generating pulsatility with pump speed modulation with continuous flow total artificial heart in awake calves, J.Artificial Organs 2017;20:381-385

16)Date K, Nishimura T, Arakawa M, Takewa Y, Kishimoto S, Umeki A, Ando M, Mizuno T, Tsukiya T, Ono M, Tatumi E. Changing pulsatility by delaying the rotational speed phasing of a rotary left ventricular assist device. J. Artificial Organs 2017; 20:18-25

17)Okada H,Masuzawa T, Matsuda K, Ohmori K, Yamane T,Konishi Y, Fukahori S, Ueno S, Kim S. Axial type self-bearing motor for axial flow blood pump Artificial Organs 2003;27:887-891 18)Nishida M, Artificial hearts_recent progress: republication of the article published in the Japanese Journal of Artificial Organs. J. Artificial Organs 2017;20(3):187-193

19)Ghadimi B, Nejat A, Nourbakhsh S, Naderi N. Shape optimiation of a centrifugal blood pump by coupling CFD with metamodel assisted genetic algorithm J.Artificial Organs 2018:Online publication October 2018

20)Smith PA, Wang Y, Bieritz SA, Samaio LC, Cohn WE, Metcalfe RW, and Frazier OH. Design method using statistical models for miniature left ventricular assist device hydraulics. Annals of Biomedical Engineering 2019;47:126-137

21)Imachi K, Mabuchi K, Chinzei T, Abe Y, Imanishi K, Yonezawa T,Isoyama T,Kouno A, Ono T, Atsumi K, Fujimasa I. The Jellyfish valve: A polymer membrane valve for the artificial heart. Heart Replacement 1993;:41-46

22)Jarvik R. Jarvik 2000 pump technology and miniaturization. Heart Failure Clinics 2014;10:2738 23)Oshita H. Transcatheter heart valve for aortic valve implantation: republication of the article 
published in the Japanese Journal of Artificial Organs. J. Artificial Organs 2018;21:125-131

Figure Caption

Figure 1 Illustration of axial flow blood pump passing through aortic valve

Figure 2(a) construction of the prototype rear-impeller axial flow blood pump

Figure 2(b) Prototype rear-impeller axial flow blood pump

Figure 3(a) Construction of miniature rear-impeller axial flow blood pump

Figure 3(b) Miniature rear-impeller axial flow blood pump

Figure 4(a) Pump performance of prototype rear-impeller axial flow blood pump

Figure 4(b) Pump performance of the miniature rear-impeller axial flow blood pump

Figure 5 Trans-valve axial flow blood pump combing miniature rear impeller axial flow blood pump with polymer monomembrane valve like jellyfish valve(21) 


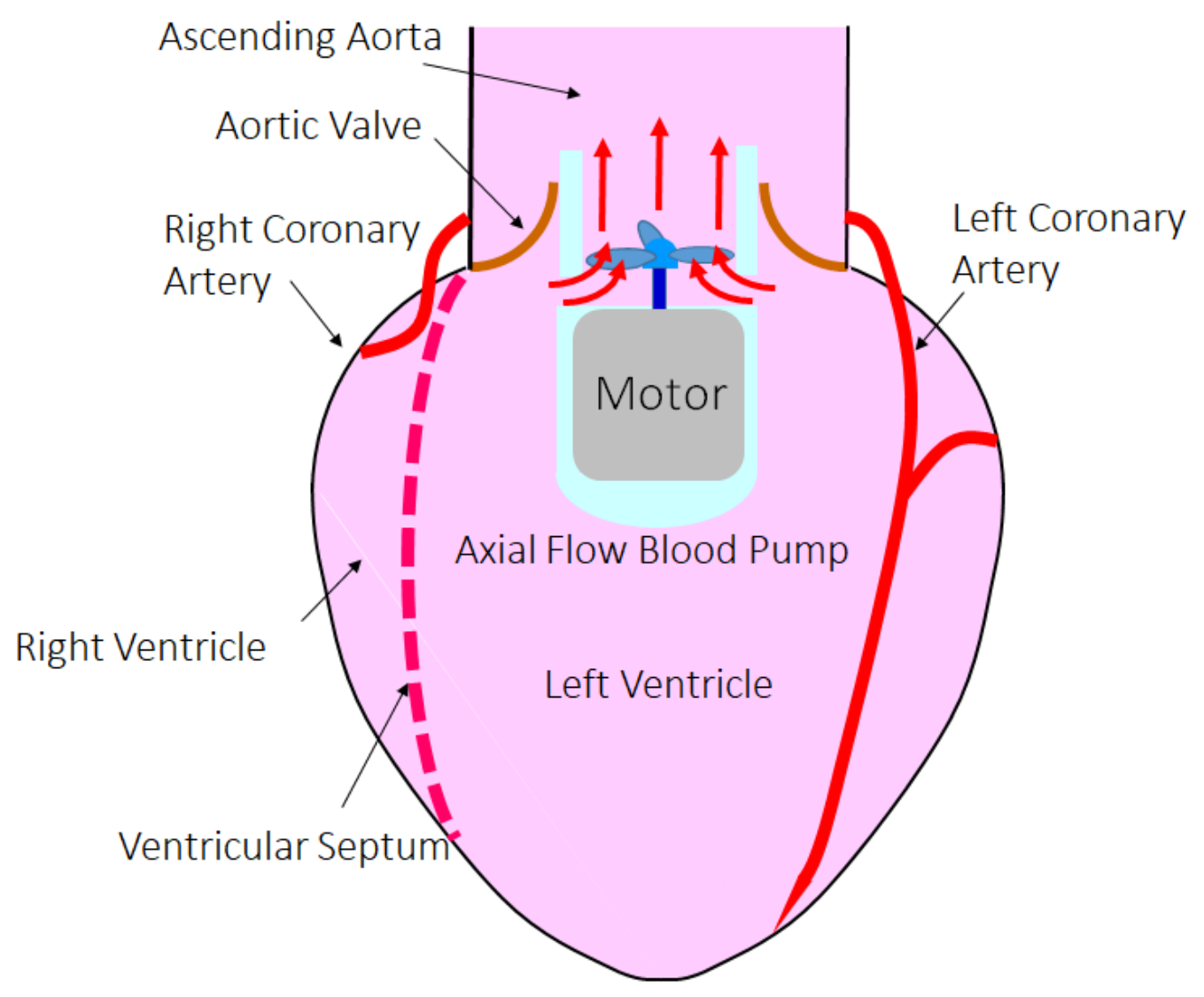

Figure 1 Illustration of axial flow blood pump passing through aortic valve

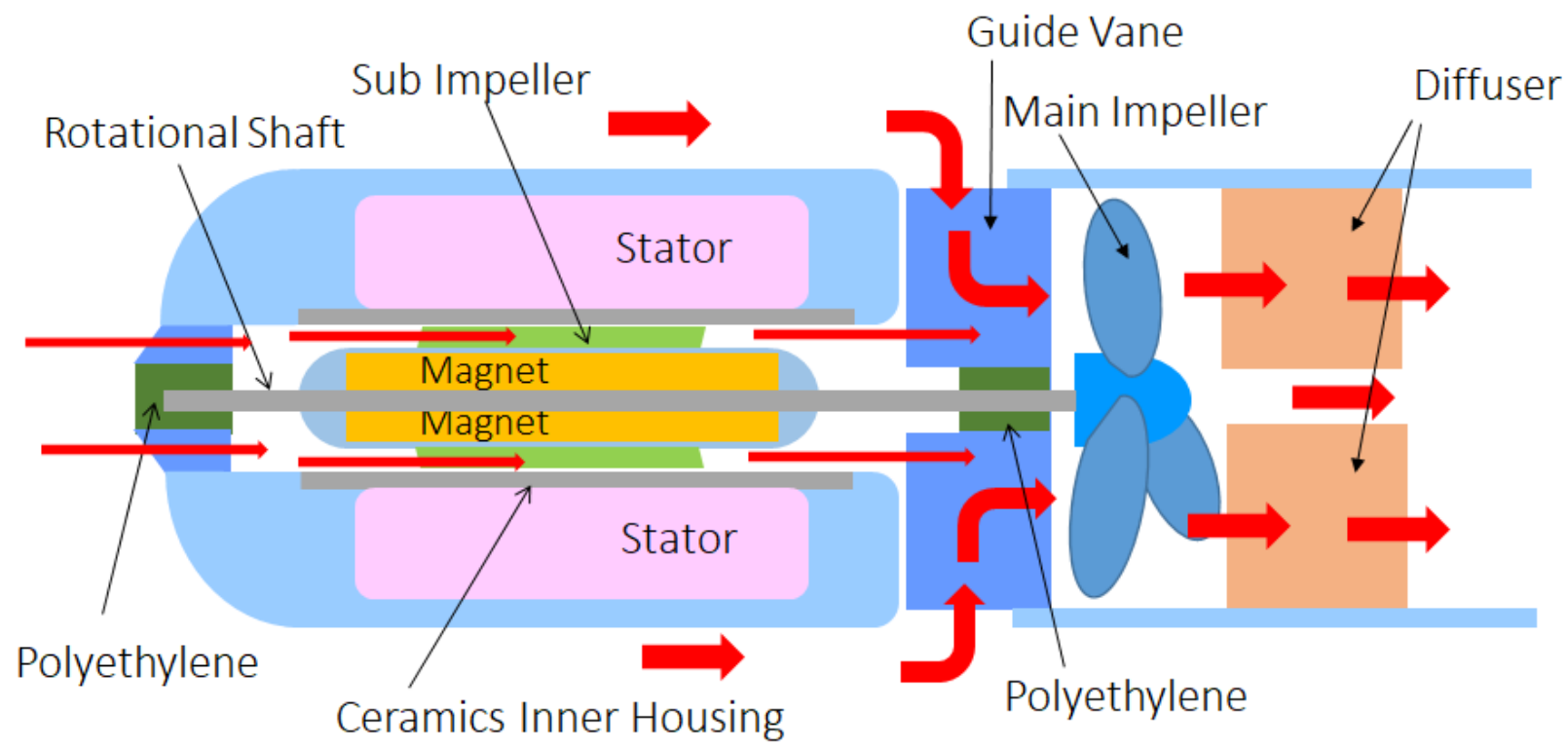

Figure 2(a) construction of the prototype rear-impeller axial flow blood pump 


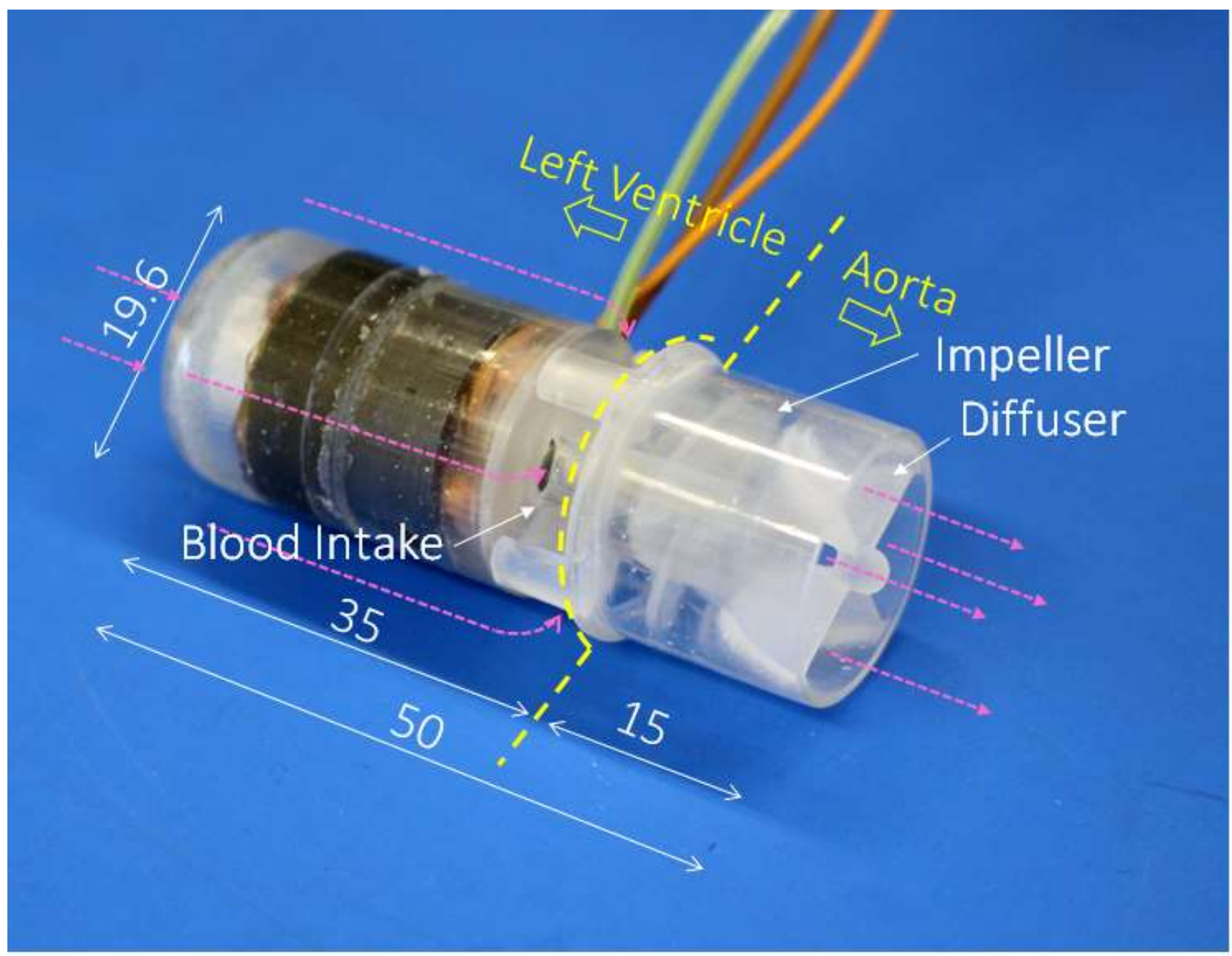

Figure 2(b) Prototype rear-impeller axial flow blood pump 


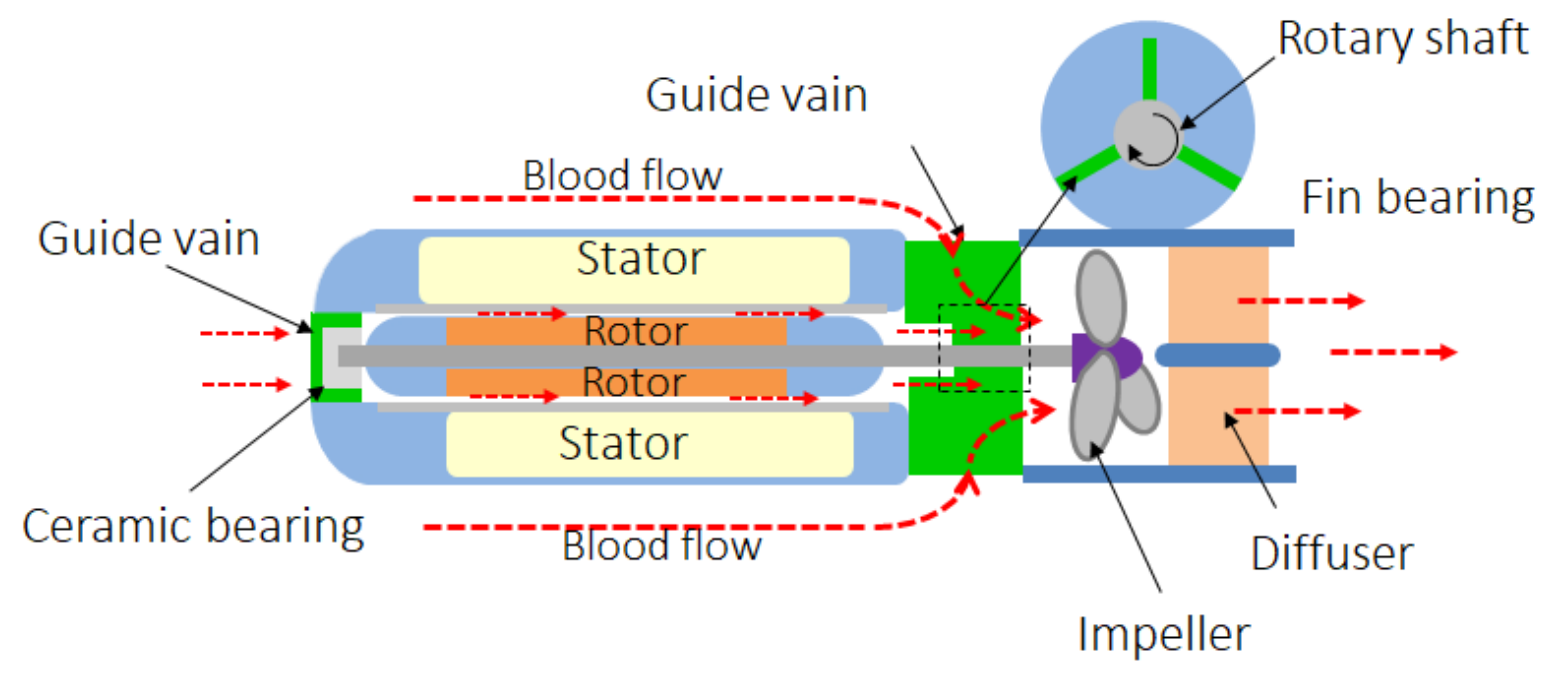

Figure 3(a) Construction of miniature rear-impeller axial flow blood pump

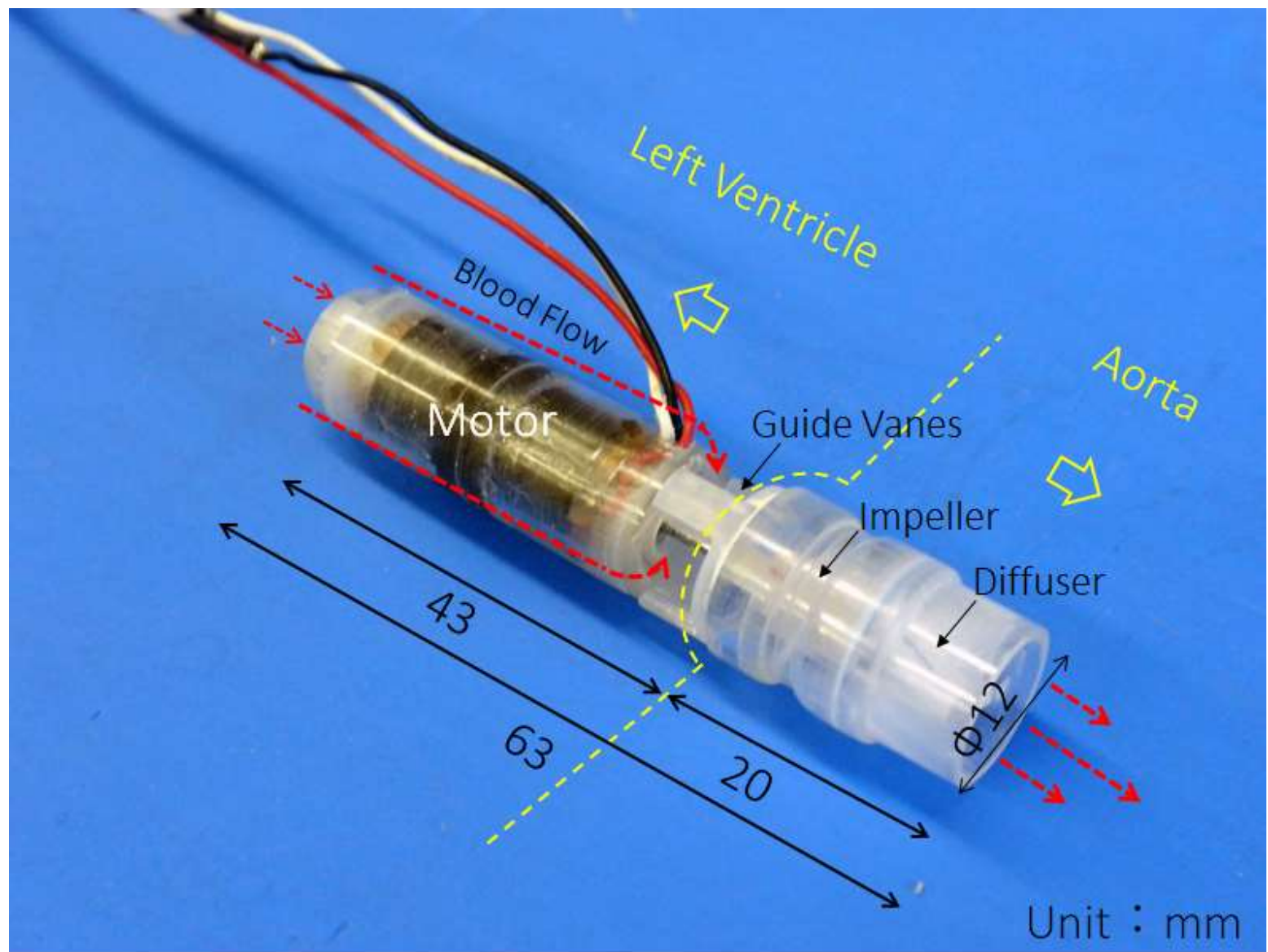

Figure 3(b) Miniature rear-impeller axial flow blood pump 


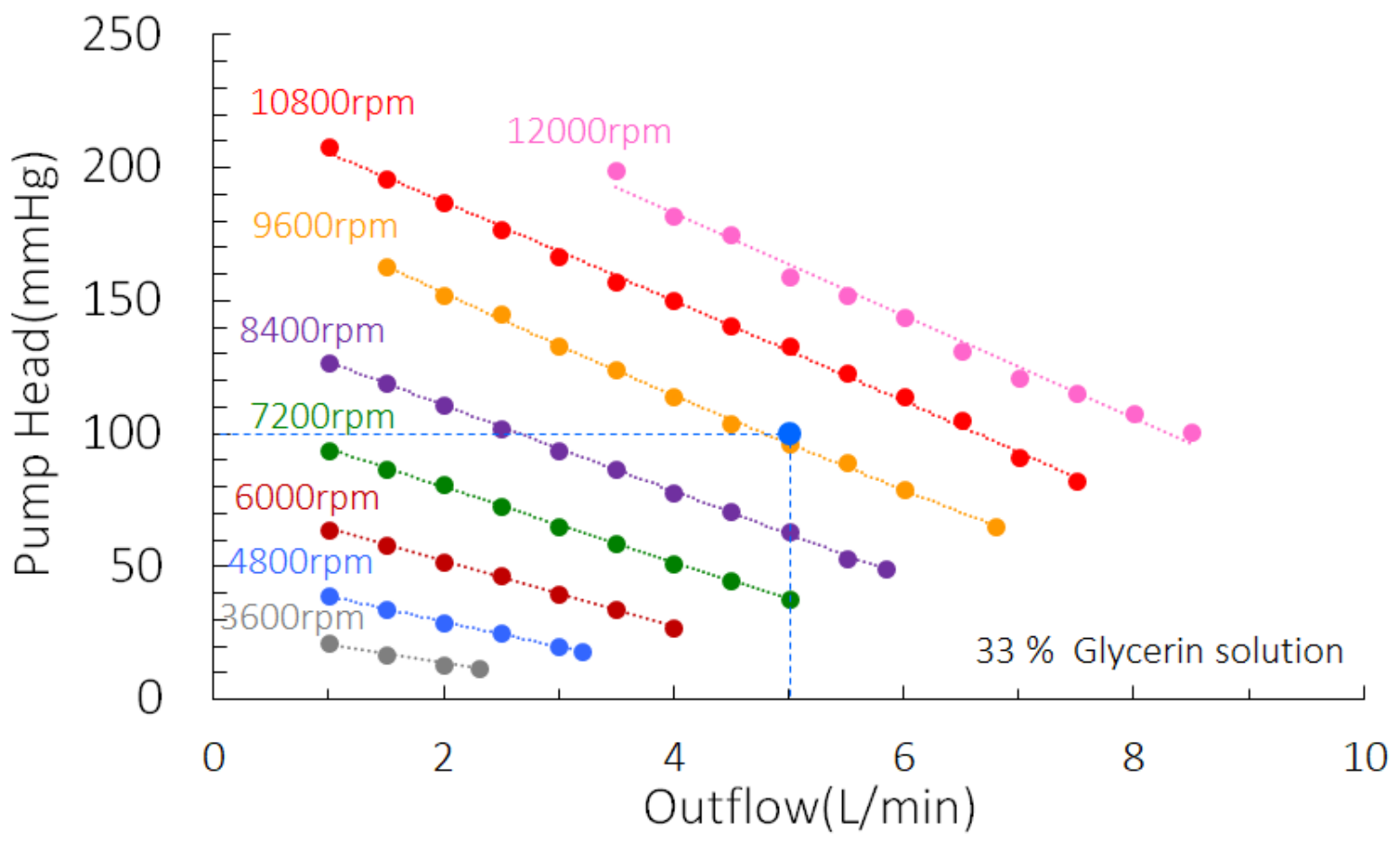

Figure 4(a) Pump performance of prototype rear-impeller axial flow blood pump

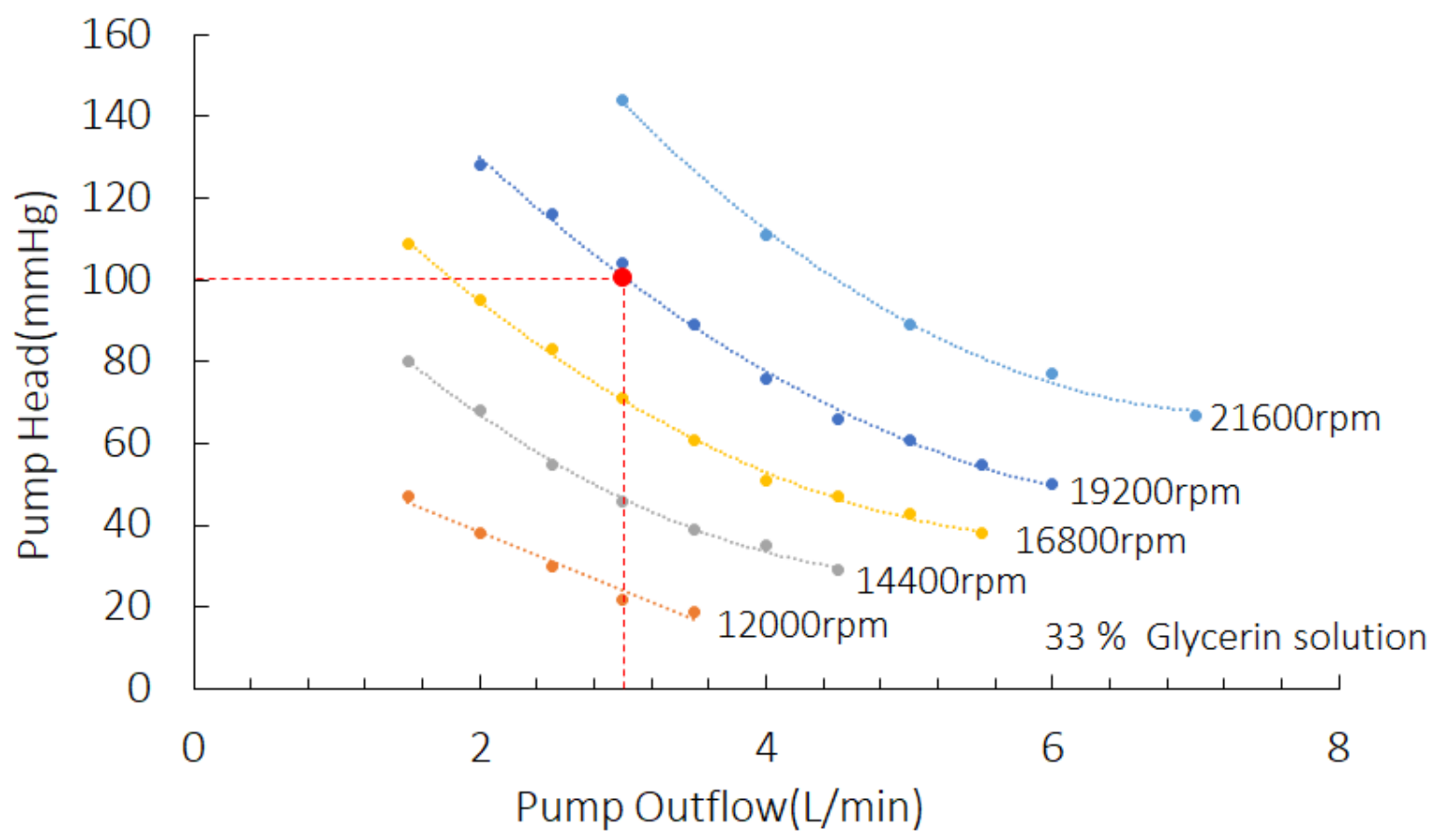

Figure 4(b) Pump performance of miniature rear-impeller axial flow blood pump 


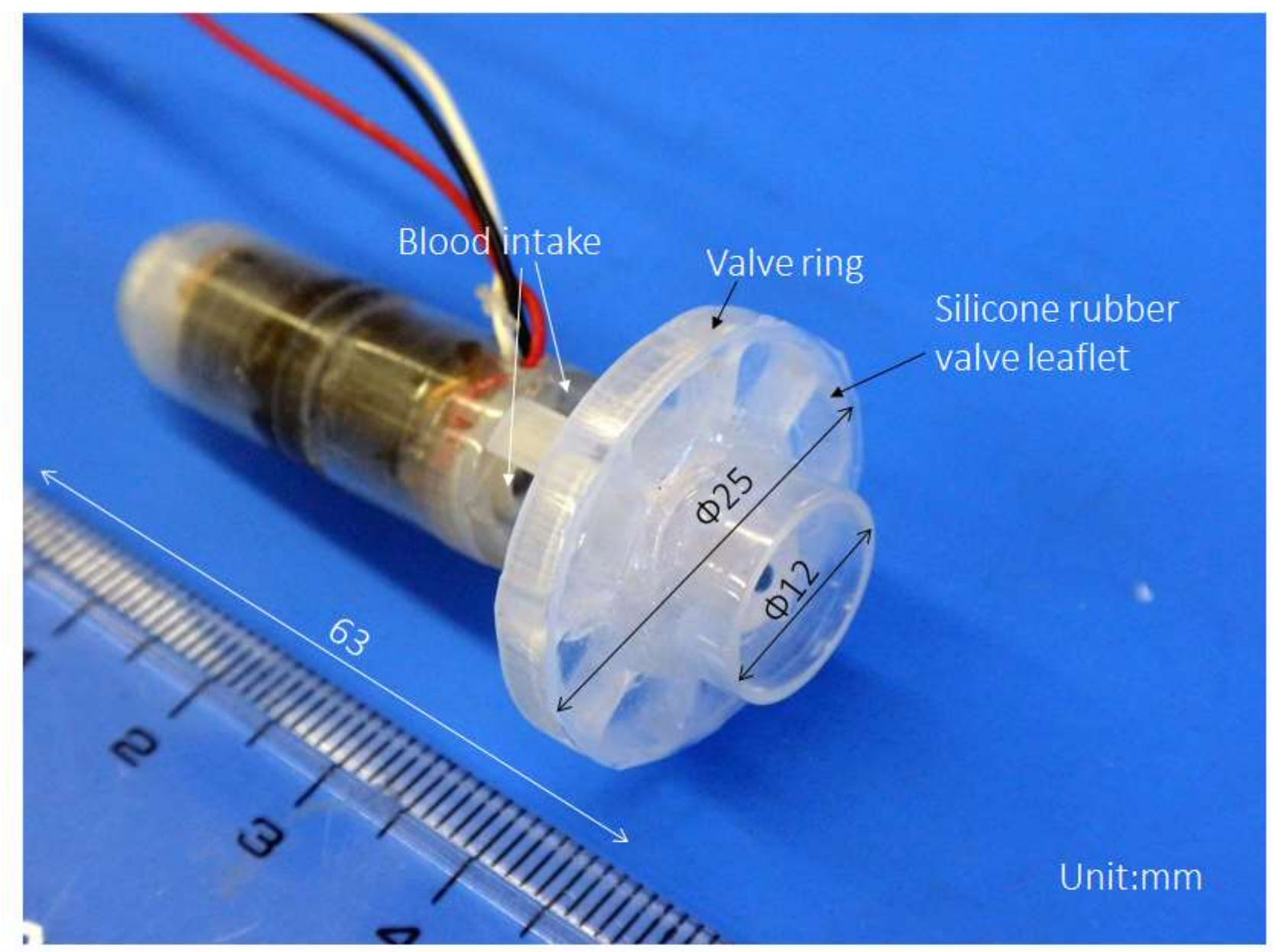

Figure 5 Trans-valve axial flow blood pump combing miniature rear impeller axial flow blood pump with polymer monomembrane valve like jellyfish valve(21) 